\title{
Comparison of Color Gamuts Among Several Types of Paper with the Same Printing Technology
}

\section{Esther Perales, ${ }^{1 *}$ Francisco M. Martínez-Verdú, ${ }^{1}$ Valentín Viqueira, ${ }^{1}$ Jesús Fernández-Reche, ${ }^{2}$ José A. Díaz, ${ }^{2}$ Joan Uroz ${ }^{3}$ \\ AQ1}

${ }^{1}$ Department of Optics, Pharmacology and Anatomy, University of Alicante, Alicante 03690, Spain
${ }^{2}$ Department of Optics, University of Granada, Campus de Fuentenueva s/n, Granada 18071, Spain

${ }^{3}$ Hewlett-Packard Española, Av. Graells 501, 08174-Sant Cugat del Vallès, Spain

Received 29 October 2007; revised 11 April 2008; accepted 7 June 2008

\begin{abstract}
In this work, we have studied the relationship among the colorimetric properties of different types of paper, having different finishing and grammage. Their color reproduction capability has also been analyzed by using the same printing technology (inkjet printing). On the one hand, we have plotted CIELAB data under the illuminant D50 into constant lightness and hue-angle planes to be compared with MacAdam limits and with Pointer's real-world surface color. On the other hand, we have calculated the volume gamut of the color solid associated to each color paper gamut. Analyzing the results, we have checked that there is not any clear relationship among the colorimetric properties of paper (for instance, CIE whiteness index, etc.) and the color gamut volume associated. However, the colorimetric parameters associated to the printed sample showed a quite good linear correlation between the minimum lightness (or the maximum blackness value) of the printed color chart and the color gamut volume. In particular, the greatest color gamut volume corresponds to the glossy papers taking into account this correlation for inkjet printing. (c) 2009 Wiley Periodicals, Inc. Col Res Appl, 00, 000-000, 2009; Published online in Wiley InterScience (www.interscience.wiley.com). DOI 10.1002/col.20506
\end{abstract}

Key words: color gamuts; color solids; printing; gloss; paper; inkjet

\footnotetext{
*Correspondence to: Esther Perales (e-mail: esther.perales@ua.es).

Contract grant sponsor: Spanish Ministry for Education and Science; contract grant number: DPI2005-08999-C02-02.
}

(C) 2009 Wiley Periodicals, Inc.

\section{INTRODUCTION}

In color reproduction, it is important to know beforehand the color gamut of reproducible colors. ${ }^{1}$ Some industries applying industrial colorimetry, such as textiles, plastic, paints, usually keep a data base with their color gamut that is reproduced in a sampler to allow the customers to judge the color generating capabilities of the manufacturer.

The Rösch-MacAdam color solid ${ }^{1,2}$ is the color solid of the human perception. The frontier colors are called optimal colors or MacAdam limits, because they were comprehensively studied by MacAdam. ${ }^{3,4}$ The optimal colors have maximum colorfulness for a given luminance factor and their spectral reflectance only has as possible values zero or one, having two transitions between these two values in all the visible spectrum. MacAdam demonstrated this theorem by assuming an equivalence between this problem and the calculation of the gravity centre in additive color mixing. Therefore, two types of optimal colors are possible: type 1, with "mountain"-like spectral profiles; and type 2, with "valley"-like spectral profiles. The optimal colors do not really exist, that is, they are not found in the real world or they can not be obtained by means of colorant formulation. Although they serve to delimit the color solid of the human perception, few companies study whether their color gamuts reach the MacAdam limits or they cover more or less homogeneously the Rösch-MacAdam color solid.

Pointer, ${ }^{5}$ in 1980 , was one of the first scientists to study this problem. In 2002, ${ }^{6}$ Pointer retook the subject, asking 
for the collaboration of all researchers interested in the matter, to generate a large database of color gamuts in current industry. Thus, it would be possible to evaluate whether there could be an increase of the real-world surface color initially defined by him.

An exhaustive study of the differences arising from the use of different inks and substrates (paper, cardboard, etc.) in the different printing technologies (flexography, gravure, offset, electrophotography, inkjet, etc.) cannot be found in the scientific literature. Thus, we are particularly interested in those aspects related to the comparison between the color gamuts of different industries with different substrates and the MacAdam limits. But also, we are interested in those aspects concerning with how the color solid is filled, either homogeneously or leaving certain void regions. Moreover, taking into account the technological advances in the colorimetric properties of the substrates and the primary colorants in recent years, it seems suitable to consider MacAdam and Pointer limits at the same time, to evaluate and compare color gamuts associated to any color reproduction system. Despite of the Pointer data are not updated, we think that it is suitable using them in any color gamuts study. In particular, we focus on this work in the qualitative comparison of color gamut of the same printing technology, but using different kinds of paper $^{7}$ from several companies. In this article, we compare the color gamut, associated to each paper, representing the printed colors at constant lightness $L^{*}$ and hue-angle $h_{\mathrm{ab}}^{*}$ planes in order to be compared with MacAdam limits and with Pointer' real-world surface color.

In a previous work, ${ }^{8}$ a first attempt was done to find a relationship between optical parameters (CIE whiteness, etc.), type of paper and color gamut. However, it has been proved recently that the volume gamut associated to color displays, ${ }^{9}$ or illuminants and lamps ${ }^{10}$ can be a good resort. Therefore, we have also calculated the color gamut volume according to different computational methods to know more exactly which paper property or parameter, such as optical or physical, or colorimetric parameter of the printed samples, has more influence on the color gamut.

\section{METHODS}

We collected a set of 29 commercial papers with different finishing and grammage, and belonging to different companies. $^{8}$ They cover several applications ranging from general, photographic, and proofing use (see Table

T1 I). The printing device selected was the inkjet printer model DesignJet 120 ps and, to evaluate the color reproduction, the ANSI IT8/7.3 color chart was printed on each of the 29 papers. However, it is worth to point out that we can widen this study for the same printing technology but using other printers. Even we can make this analysis with other printing technology such as electrophotographic, gravure, flexography, etc. ${ }^{11-13}$
TABLE I. Set of papers used in the study.

\begin{tabular}{|c|c|c|c|}
\hline Paper & Finishing & Use & $\begin{array}{c}\text { Grammage } \\
\left(\mathrm{g} / \mathrm{m}^{2}\right)\end{array}$ \\
\hline 1 & Glossy/satin & Photo paper & 195 \\
\hline 2 & Glossy/satin & Photo paper & 195 \\
\hline 3 & Glossy & Proof paper & 150 \\
\hline 4 & Matte & Proof paper & 120 \\
\hline 5 & Coated semi-matte & Proofing & 180 \\
\hline 6 & Glossy & Proofing & 172 \\
\hline 7 & Semi-matte & Proofing & 154 \\
\hline 8 & Glossy & Proofing & 260 \\
\hline 9 & Semi-matte & Proofing & 260 \\
\hline 10 & Coated matte & General & 89 \\
\hline 11 & Coated matte & Photo/proofing & 105 \\
\hline 12 & Coated glossy & Photo paper & 215 \\
\hline 13 & Matte & General & 192 \\
\hline 14 & Coated matte & Photo/proofing & 167 \\
\hline 15 & Glossy & Proofing & 190 \\
\hline 16 & Glossy & Photo paper & 255 \\
\hline 17 & Glossy & Photo paper & 230 \\
\hline 18 & Glossy & Photo paper & 240 \\
\hline 19 & Semi-glossy & Proofing & 150 \\
\hline 20 & Glossy & Proofing & 175 \\
\hline 21 & Matte & Proofing & 158 \\
\hline 22 & 2-Sided matte finish & General & 135 \\
\hline 23 & 2-Sided gloss & General & 160 \\
\hline 24 & Matte & General & 100 \\
\hline 25 & Bright white & General & 90 \\
\hline 26 & Glossy & Photo paper & 240 \\
\hline 27 & Glossy & Proofing & 140 \\
\hline 28 & Glossy & Proofing & 147 \\
\hline 29 & Glossy & Photo paper & 270 \\
\hline
\end{tabular}

The spectral reflectance, $\rho(\lambda)$, of the each ANSI IT8/ 7.3 color chart patch was measured using a Gretag Spectroscan Spectrolino spectrophotometer ${ }^{8}$ and was encoded by CIE-1931 XYZ standard observer under illuminant D50. Then, the CIELAB descriptors $L^{*}, a^{*}, b^{*}, C_{\mathrm{ab}}^{*}, h_{\mathrm{ab}}^{*} 14$ were computed. Taking into account the MacAdam limits under $\mathrm{D} 0^{10}$ and Pointer' real-world surface color previously transformed by the CAT02 transform of the CIECAM02 color appearance model, ${ }^{15}$ we can select the constant lightness $L^{*}$ and the constant hue-angle $h_{\mathrm{ab}}^{*}$ profiles in which the samples of each color gamut with different paper and the MacAdam and Pointer loci must be plotted. That is, once all the patches of each gamut color are measured, the CIELAB data are grouped in parallel ordering them by increasing lightness $L^{*}$ and hue-angle $h_{\mathrm{ab}}^{*}$. Then, CIELAB data are plotted into constant lightness (luminance factor) planes with a variance of $\Delta L^{*}= \pm 5$. On the other hand, the same CIELAB data now ordered by hue are plotted into constant hue-angle planes with a variance $\Delta h^{*}$ associated to the hue-angle range of the major hues of the Munsell notation (R, YR, Y, GY, etc). ${ }^{5}$

Once the qualitative comparison with the MacAdam and Pointer limits will be done, we will show a quantitative study based on the volume gamut. For this, we will plot all the reproduced samples associated to each paper into a three-dimensional structure with axes $a^{*}, b^{*}$, and $L^{*}$. Then, we also will plot the color solid calculating the borders by means of different geometric computational approaches: by using a convex hull of the color space data and by using the alpha-shapes technique, which is a 

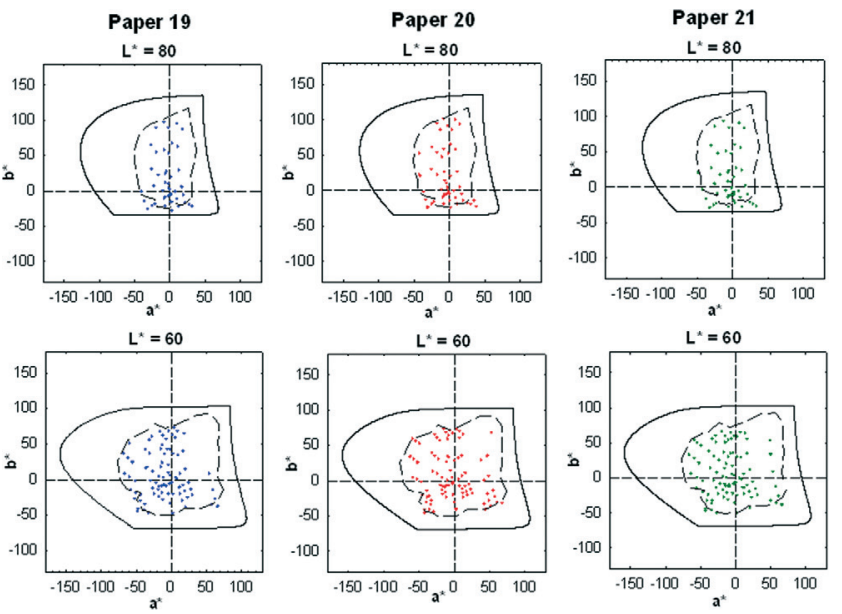

C

$\mathrm{O}$

L

$\mathrm{O}$

$\mathrm{R}$
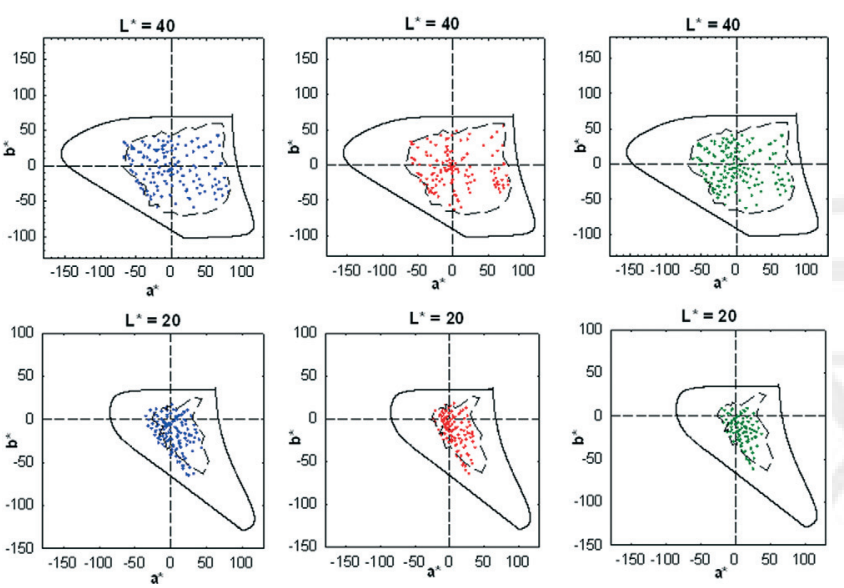

FIG. 1. Color gamut of three papers: semi-glossy finishing and grammage of $150 \mathrm{~g} / \mathrm{m}^{2}$ (left), glossy finishing and grammage of $175 \mathrm{~g} / \mathrm{m}^{2}$ (center), and matte finishing and grammage of $158 \mathrm{~g} / \mathrm{m}^{2}$ (right). The solid line corresponds to the MacAdam limits and the dashed line is for the Pointer's real-world surface color.

generalization of a convex hull method applicable also to nonconvex solids. Thus, we can calculate the volume associated to this color solid. ${ }^{9,16-18}$

\section{RESULTS AND DISCUSSION}

\section{Qualitative Analysis Based on the Comparison Among Color Gamuts}

We show a first comparison among the color gamuts obtained from each type of paper according to several lightness values. We have compared the color gamut associated to all papers to determine which paper reproduces a better color gamut, that is, which color gamut reaches more MacAdam limits and, moreover, it fills more homogeneously these limits. We also have compared the color gamuts with Pointer's real-world surface color to assess if the color gamut associated to the present printing technology offers a wider color gamut.

We have chosen several lightness profiles $\left(L^{*}=20\right.$, $40,60,80)$, so that there are dark and light colors, and those having intermediate lightness. In the Fig. 1, it is shown an example of the color gamut comparison at constant lightness planes. In this case, we have plotted the color gamut associated to three papers having different grammage: 150,175 , and $158 \mathrm{~g} / \mathrm{m}^{2}$, with semi-glossy, glossy, and matte finishing, respectively (papers: 19, 20, 21, see Table I).

As it can be seen for this example, there are not many differences among the three papers. None of the papers reach the MacAdam limits at any constant planes and the color gamut associated to these papers is very similar to the Pointer's real world surface color, although there are more blue or cyan colors at some constant lightness planes. Furthermore, we can see that there is a reduction of dark colors in matte paper (paper 21). And, from this comparative, we could say that the color gamut is slightly larger for the paper with semi-glossy finishing.

After assessing all the papers with this method, we have checked that the main differences are found in lowlightness profiles. Thus, from this first analysis, we believe that there could be some correlation between the color gamut and the lightness value. In addition, the wider
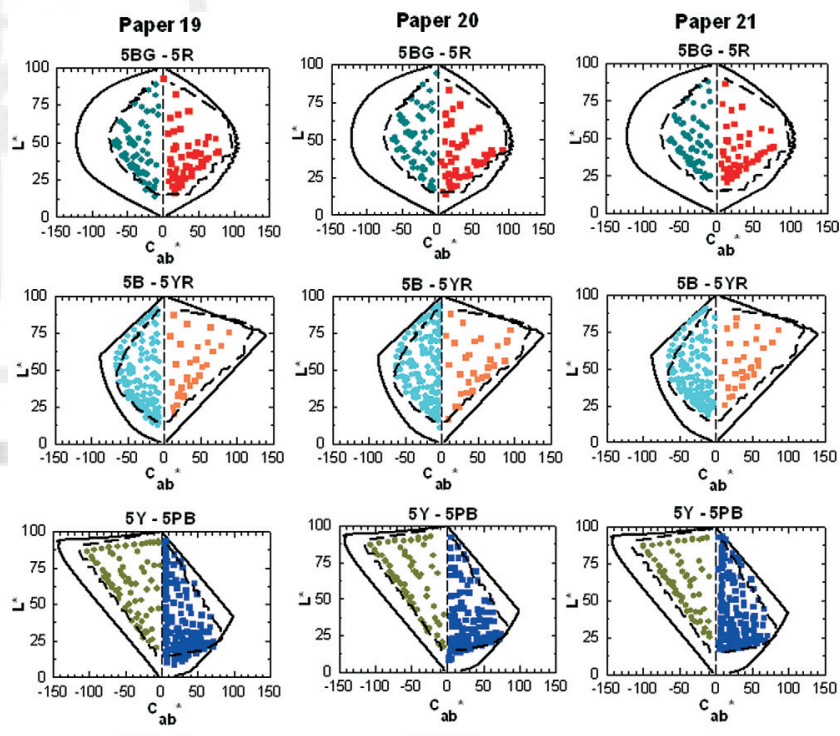

$5 G Y-5 P$
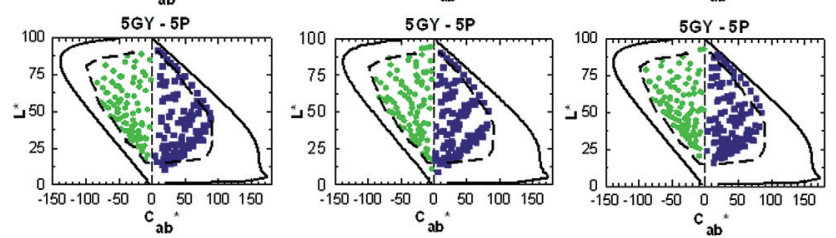

$\mathrm{O}$

L

$\mathrm{O}$
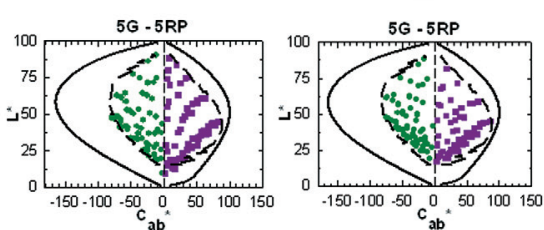

FIG. 2. Color gamut of three papers belonged to the same company: semi-glossy finishing and grammage of $150 \mathrm{~g} / \mathrm{m}^{2}$ (left), glossy finishing and grammage of $175 \mathrm{~g} / \mathrm{m}^{2}$ (center), and matte finishing and grammage of $158 \mathrm{~g} / \mathrm{m}^{2}$ (right). The solid line corresponds to the MacAdam limits and the dashed line is for the Pointer's real-world surface color. 
TABLE II. Volume obtained by means of the convex hull and alpha shape algorithm for the color solid defined for each paper.

\begin{tabular}{|c|c|c|c|c|c|}
\hline Paper & Finishing & Use & $\begin{array}{l}\text { Grammage } \\
\qquad\left(\mathrm{g} / \mathrm{m}^{2}\right)\end{array}$ & $\begin{array}{c}\text { Volume } \\
\text { (convex hull) }\end{array}$ & $\begin{array}{c}\text { Volume } \\
\text { (alpha-shapes) }\end{array}$ \\
\hline 1 & Glossy/satin & Photo paper & 195 & 812,420 & 761,000 \\
\hline 2 & Glossy/satin & Photo paper & 195 & 744,890 & 693,010 \\
\hline 3 & Glossy & Proof paper & 150 & 612,780 & 522,130 \\
\hline 4 & Matte & Proof paper & 120 & 535,020 & 458,410 \\
\hline 5 & Coated semi-matte & Proofing & 180 & 657,660 & 600,750 \\
\hline 6 & Glossy & Proofing & 172 & 619,050 & 508,810 \\
\hline 7 & Semi-matte & Proofing & 154 & 636,750 & 590,190 \\
\hline 8 & Glossy & Proofing & 260 & 735,520 & 658,180 \\
\hline 9 & Semi-matte & Proofing & 260 & 675,350 & 606,720 \\
\hline 10 & Coated matte & General & 89 & 487,870 & 398,570 \\
\hline 11 & Coated matte & Photo/proofing & 105 & 494,980 & 449,210 \\
\hline 12 & Coated glossy & Photo paper & 215 & 716,800 & 605,380 \\
\hline 13 & Matte & General & 192 & 562,160 & 504,570 \\
\hline 14 & Coated matte & Photo/proofing & 167 & 557,860 & 519,570 \\
\hline 15 & Glossy & Proofing & 190 & 759,840 & 654,810 \\
\hline 16 & Glossy & Photo paper & 255 & 760,680 & 640,970 \\
\hline 17 & Glossy & Photo paper & 230 & 818,980 & 743,960 \\
\hline 18 & Glossy & Photo paper & 240 & 762,080 & 704,260 \\
\hline 19 & Semi-glossy & Proofing & 150 & 634,490 & 458,770 \\
\hline 20 & Glossy & Proofing & 175 & 640,960 & 581,930 \\
\hline 21 & Matte & Proofing & 158 & 583,590 & 542,620 \\
\hline 22 & 2-Sided matte finish & General & 135 & 492,340 & 429,870 \\
\hline 23 & 2-Sided gloss & General & 160 & 534,290 & 476,480 \\
\hline 24 & Matte & General & 100 & 500,670 & 442,790 \\
\hline 25 & Bright white & General & 90 & 308,460 & 267,350 \\
\hline 26 & Glossy & Photo paper & 240 & 691,220 & 630,340 \\
\hline 27 & Glossy & Proofing & 140 & 631,410 & 536,300 \\
\hline 28 & Glossy & Proofing & 147 & 634,470 & 529,990 \\
\hline 29 & Glossy & Photo paper & 270 & 629,110 & 547,140 \\
\hline
\end{tabular}

color gamut is generally associated to glossy papers and to papers with high grammage. The color gamut of matte paper is lower because uncoated papers give a lower density $(D)$ because of their greater ink absorption, this resulting a loss of saturation, that is, the worst color gamut. Compared with the glossy papers, these have the highest color density $\left(D_{\max }\right)$, and therefore the widest color gamut. Along the same line, papers with higher grammage have more absorption capability, therefore more ink can be put on them and as result the color gamut is wider. ${ }^{11,17}$ Regarding the semi-matte/semi-glossy papers, we have also checked that we get results comparable with glossy paper, in terms of gamut volume. Finally, we have shown that the zone defined by the MacAdam limit is not covered by any studied paper by using inkjet technology, and that the color gamut obtained with the printer used and associated to the different papers is not much wider than the maximum real world surface color defined by Pointer in 1980 .

Now, we concern the reproduced colors by the printer in each paper in constant hue planes. We plot them by choosing the 10 principal profiles from Munsell Atlas $\left(\Delta h^{*}=36^{\circ}\right)$ and we show graphics with axis labels $C^{*}$ versus $L^{*}$. As in the previous section, we show only an example for this analysis: the comparison among the papers numbered 19, 20, and 21 .

F2 In this comparative (Fig. 2), again we can say that color gamut with matte paper is smaller than for the other ones. The difference between semi-glossy and glossy paper is that the glossy paper reproduces better the black, that is, we obtain more dark colors with this paper than with the other ones. This is because the matte characteristics of the surface add a diffuse white component, ${ }^{11,17}$ therefore samples are not saturated and the lightness value is higher. In addition, we have also checked that none of them reaches the MacAdam limits. Furthermore, the Pointer's real-world surface color is very similar to the color gamut associated to each paper although, as we have said in the previous comparison, there are more blue colors with higher lightness.

After this analysis for all studied papers, we do observe that none of the paper, independently of its grammage or finishing, reaches the MacAdam limits completely. The color gamut reproduced by this printer for each paper is not much wider than the Pointer's real-world surface color. The differences between the color gamuts associated to glossy paper and semi-glossy/semi-matte paper are very similar. Thus, from this analysis, we can not say that there is some gamut advantage in the color reproduction if we use glossy paper instead of semi-matte/semi-glossy paper. We also have observed that the main difference among papers is their capability to reproduce dark colors, so we think that if we get lower lightness values or greater blackness values, we will get a greater color gamut.

\section{Quantitative Analysis Based on Color Gamut Volume}

In the previous section, we have qualitatively assessed the color gamut analyzing different profiles of lightness 

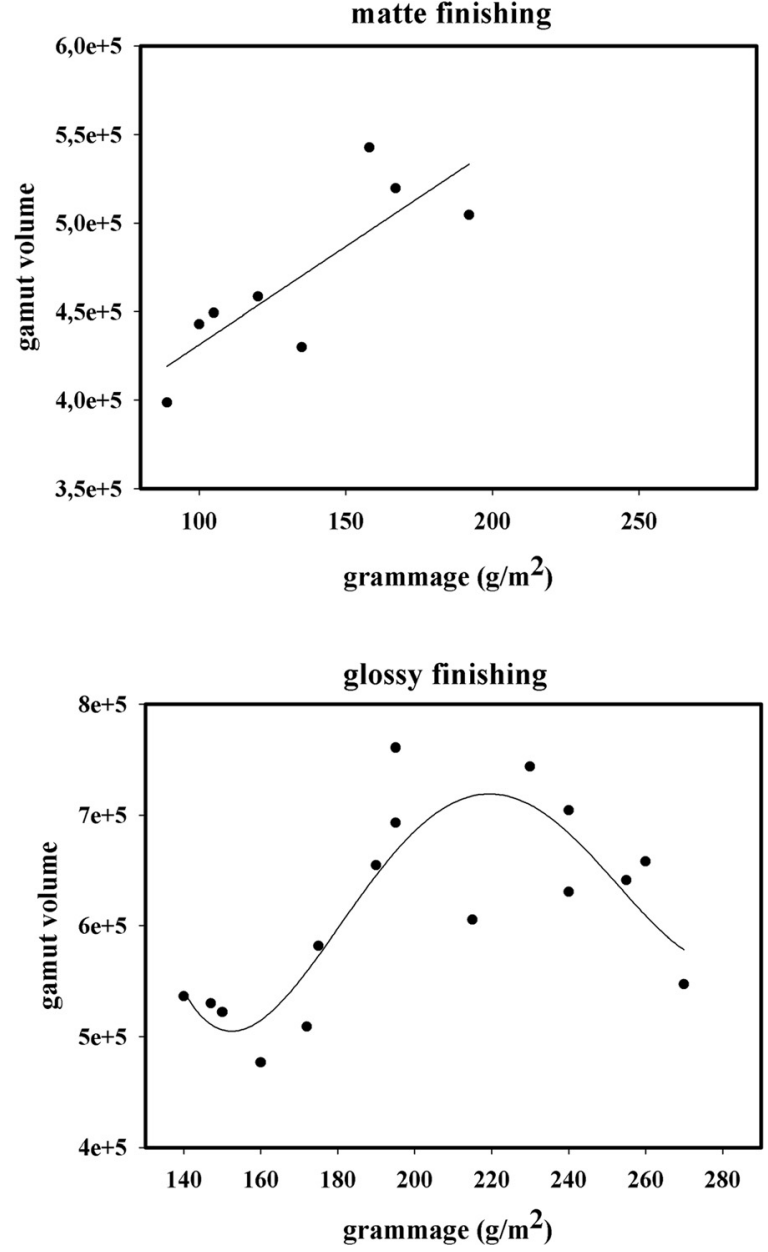

FIG. 3. Change in the color solid volume with the grammage for matte papers (top) and glossy paper (bottom).

and hue-angle. Here, we do a quantitative study that determines the color solid volume by using the convex hull and alpha-shapes algorithms. ${ }^{16-18}$ This allows to check the previous results and to know in a more precise manner the color gamut offered by each paper. In addition, we want to know if there is some relationship among the colorimetric properties of the paper and the color solid volume, and among the grammage, the finishing, and the color solid volume.

In Table II, we present the color solid volume determined for the 29 papers used in this work by using both algorithms. We have checked that the convexity assumption causes an overestimation of the gamut volume. ${ }^{19}$ For this reason, we only focus on the results obtained with the alpha-shapes method. The widest color gamut calculating with this method is for the paper 1, with grammage of $195 \mathrm{~g} / \mathrm{m}^{2}$ and glossy finishing. The paper 25, bright white finishing and $90 \mathrm{~g} / \mathrm{m}^{2}$, shows the lowest color solid volume.

With these data, now we can check if there is a progressive increase of the color solid volume with an increase in the paper grammage, as it is expected from previous analyses. We show two plots of volume versus grammage, each one associated to papers with different finishing (glossy and matte finishing) (Fig. 3). As we can see in the Fig. 3, there is an increasing trend between grammage and volume for matte papers, whereas for glossy papers there is not a linear correlation between grammage and gamut volume. The reason has to be found in the different absorption capabilities of these papers. In coated papers, the ink penetrates very deeply in the paper, and for this reason, the thicker the paper, the more ink can be layed down on it, and the more gamut can be obtained. ${ }^{11,17}$ However, we do not have enough semiglossy/semi-matte papers to observe the relation between
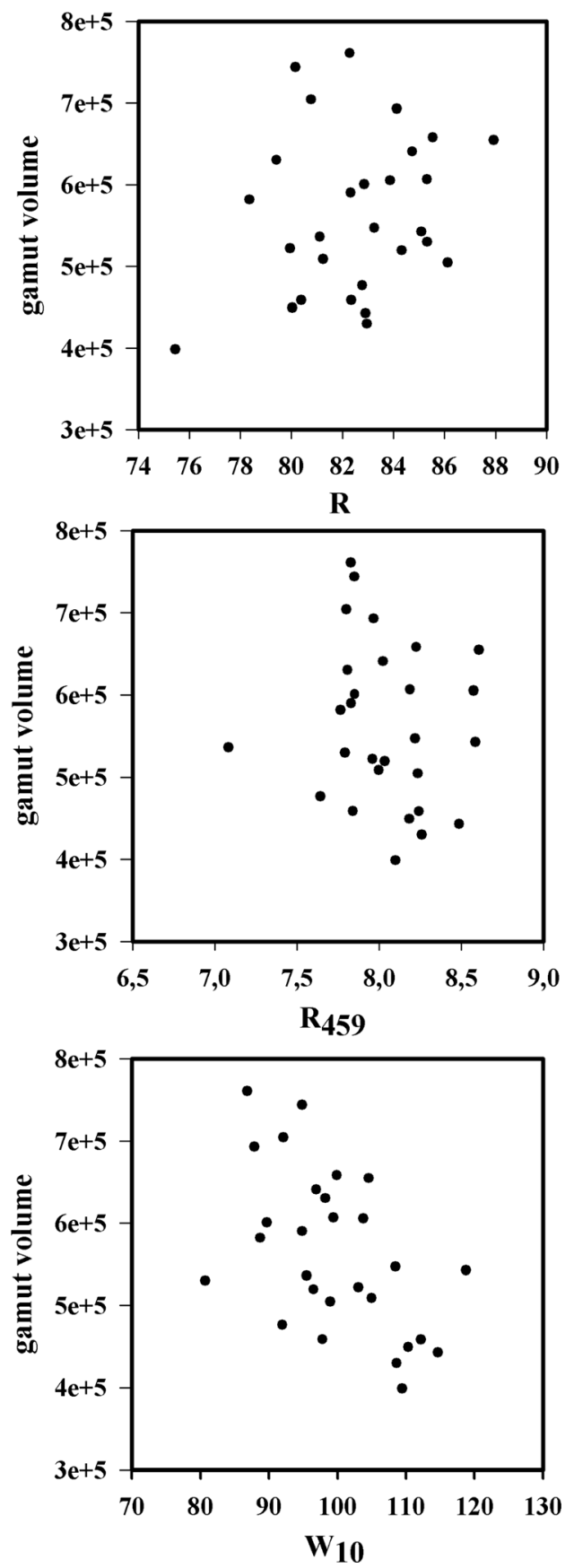

FIG. 4. Relation among the diffuse reflectance factor, $R$, (top), the ISO brightness, $R_{457}$, (centre), and the CIE whiteness, $W_{10}$, (bottom) with the color solid volume. 

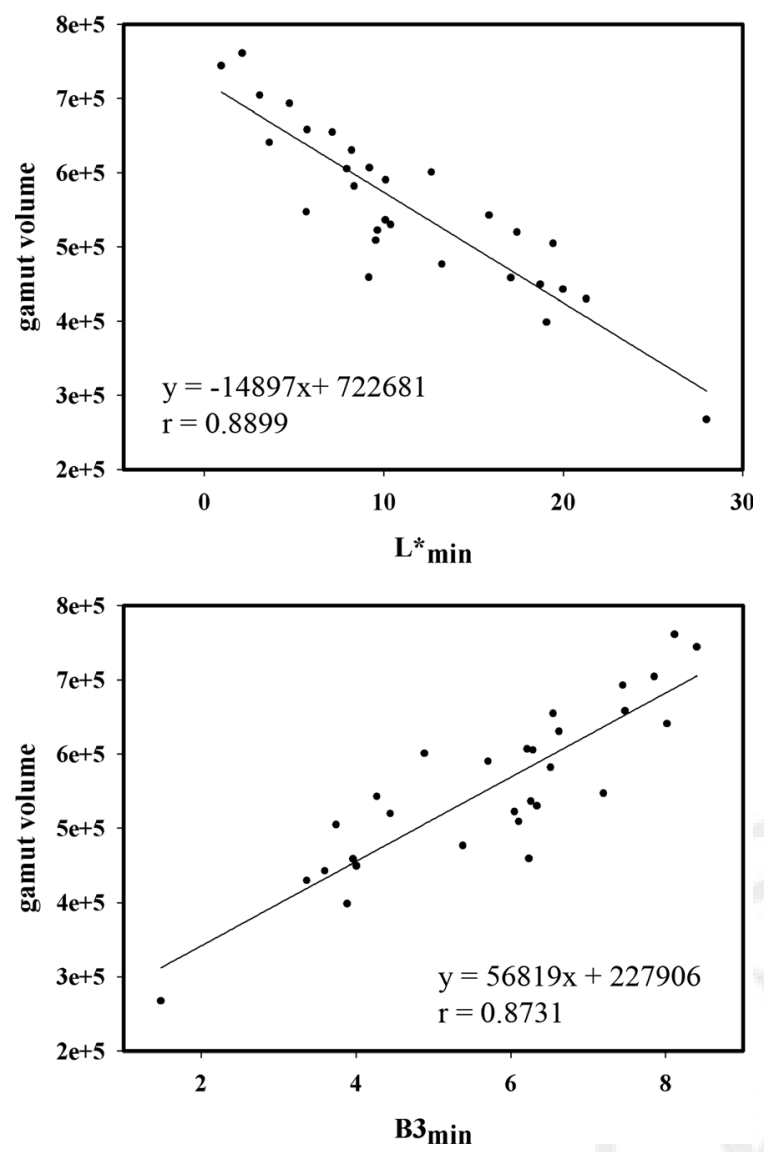

FIG. 5. Correlation among the minimum lightness value, the maximum blackness value and the color solid volume.

these variables. In spite of the fact that we have obtained these results with this printer device, we could obtain similar results with other printers or with other printing technologies, so this study could be applied to compare different printing technologies with the same substrates or vice versa, or even different printing devices with the same technology.

In addition, we have done a similar study to quantify the color gamut of the different papers according to other parameters which characterize the paper. In this way, we could know if there is some relationship between the color gamut and the following characteristics ${ }^{8}$ :

- the diffuse reflectance factor, $R$

- the ISO brightness, $R_{457}$

- the CIE whiteness index, $W_{10}$

In Fig. 4, we can observe that there is not any relationship among these parameters and the total color solid volume associated to each studied paper. Thus, from this discrete set of papers, we can not evaluate what optical characteristics would have more influence on the color gamut or if these parameters would affect in the obtained color gamut. Therefore, it might be necessary a more exhaustive study, based on a statistical approach, to determine how the color gamut is affected by these optical parameters.
As in the above qualitative analysis, we have seen that the main difference among the papers lays on its capability to reproduce dark colors. Next, we have studied the relationship between the color solid volume and colorimetric parameters which can be related to dark colors, as it could be the lightness $L^{*}$ and a new perceptual blackness index $\mathrm{B} 3,{ }^{20}$ in terms of assessment of a black color in the printed samples. The blackness metric is based on the CIE whiteness metric, it is a linear combination of luminance and chromatic coordinates, and the coefficients were determined by optimization between this index and the psychophysical experiments. As it can be seen in the Fig. 5, there is a clear linear correlation among these parameters and the color solid volume. We can say that the papers that reproduce more dark colors will have a wider color gamut, as glossy papers as matte and semi-matte/ glossy papers.

\section{CONCLUSIONS}

In this work, we have presented a methodology to compare and evaluate color gamuts in printing technologies. We can evaluate the color gamut offered by different printer devices belonging to the same printing technology or we can evaluate the color reproduction capability of different printing technologies. But, we can also use a different color chart (ECI 2002, etc.) to evaluate the color reproduction, and thus, this methodology can be applicable for any comparison of industrial color gamuts.

After comparing all papers, we have checked that the color gamuts are very similar, although we have not been able to compare papers with the same finishing and grammage exactly. Some of them differed over the best black reproduction, but the color gamut associated to these papers does not reach the MacAdam limits and neither it is much wider than the real-world surface color defined by Pointer in 1980 .

Regarding the comparison of color gamuts associated to papers from the same company, we have shown that the colorimetric rendering is higher slightly for glossy papers, but we have to take into account that there are not many differences between glossy and semi-matte finishing.

Comparing papers with the same finishing but with different grammage, in general, all the MacAdam limits are relatively well filled, but we have shown that a smaller grammage implies a worse reproduction of black color in matte paper.

The color gamut, understood as a combination between the paper and the printer technology, depends on the grammage and the finishing. We think that more research is necessary to know what parameter (grammage or finishing) is involved in the most variation in the color gamut. To assess this, we must relate the area of color gamut with a numerical variable associated with the grammage and finishing. 
Considering the results on the color solid volume calculations, we have checked that the correlation between the grammage and the volume is not linear. Moreover, we have observed that there is not any relation among the color gamut and colorimetric parameter which characterize a paper, as the CIE whiteness, the diffuse reflectance factor or the ISO brightness. This might be due to these optical parameters are directly associated to the white vertex of the color solid. However, in this work, we have checked that the color gamuts associated to different finishing increase because the black vertex darkens. Therefore, it could be necessary to determine an optical parameter of papers associated to their blackness, or their absorption ability of black ink in the surface, to find an optical parameter directly associated with color reproduction ability.

Moreover, we have shown that there is a good correlation between the minimum lightness (or the maximum blackness value) and the gamut of reproducible colors. Thus, we believe that more research is necessary to obtain new dyes and pigments in printing technologies and paper industry for trying get more dark colors, because at this moment, the main problem is to cover the base of the color solid.

\section{ACKNOWLEDGMENTS}

Esther Perales would like to thank the Spanish Ministry for Education and Science for the Ph.D. grant that she has received.

1. Berns RS. Billmeyer and Saltzman's Principles of Color Technology. New York: John Wiley; 2000.

2. Kuehni RG. Color Space and Its Divisions: Color Order from Antiquity to the Present. New York: John Wiley; 2003.

3. MacAdam DL. Maximum visual efficiency of coloured materials. J Opt Soc Am 1935;25:316-367.

4. MacAdam DL. The theory of the maximum visual efficiency of colour materials. J Opt Soc Am 1935;25:249-252.
5. Pointer MR. The gamut of real surface colors. Color Res Appl 1980;5:145-155.

6. Pointer MR. Request for real surface colors. Color Res Appl 2002;27:374.

7. Baudin G, Rousset E. Inkjet printing: Effect of paper properties on print quality. Proceeding in NIP17: International Conference on Digital Printing Technologies, 2001. p 123-124.

8. Fernández-Reche J, Uroz J, Díaz JA, García-Beltrán A. Color reproduction on inkjet printers and paper colorimetric properties. Proceeding SPIE 2003;5293:101-109.

9. CIE. Method of Measuring and Specifying Colour Rendering Properties of Light Sources. CIE Publication 13.3; 1995.

10. Martínez-Verdú FM, Perales E, Chorro E, Fez D, Viqueira V, Gilabert E. Computation and visualization of the MacAdam limits for any lightness, hue angle and light source. J Opt Soc Am A 2007;24:1501-1515.

11. Kipphan H. Handbook of Print Media: Technologies and Production Methods. Berlin: Springer; 2001.

12. Smyth S. The Print and Production Manual. Leatherhead: Pira; 2003.

13. Thompson B. Printing Materials: Science and Technology. London: Pira International; 2004.

14. Wyszecki G, Stiles WS. Color Science: Concepts and Methods, Quantitative Data and Formulae: New York. John Wiley; 1982.

15. CIE. A Colour Appearance Model for Colour Management Systems: CIECAM02. CIE Publication 159; 2004.

16. Guyler K. Visualization of expanded printing gamuts using 3-dimensional convex hulls. Proceedings of TAGA, 2000. p 696-708.

17. Doll P. 3-Dimensional color gamut quantification and comparison, Vol.17. Proceedings of NIP17: International Conference on Digital Printing Technologies, 2001. p 804-807.

18. Cholewo TJ, Love S. Gamut boundary determination using alphashapes. Proceedings of the 7th Color Imaging Conference: Color Science, Systems and Applications, 1999; p 200-204.

19. Bakke AM, Hardeberg JY, Farup I. Evaluation of gamut boundary descriptors. Proceedings of the 14th Color Imaging Conference: Color Science, Systems and Applications, 2006; p 51-55.

20. Westland S, Cheung TLV, Lozman OR. A metric for predicting perceptual blackness. Proceedings of the IS\&T/SID's Fourteenth Color Imaging Conference, 2006; p 14-17.

21. Green P, MacDonald LW. Color Engineering: Achieving Device Independent Color. Chichester: John Wiley; 2002.

22. MacDonald LW, Luo MR. Color Image Science: Exploiting Digital Media. Chichester: John Wiley; 2002.

23. Wandell BA, Silverstein DL. Digital Color Reproduction. New York: Shevell, Science of Color; 2003. 
AQ1: Please confirm that all author names are OK and are set with first name first, surname last.

AQ2: Kindly check whether the affiliations are OK as typeset.

AQ3: Please note that the references 21-23 (originally numbered 7-9, respectively) were not cited anywhere in the text and have therefore been kept at the end. Can these be deleted? If they need to be inserted anywhere in the text, kindly renumber all citations and references accordingly.

AQ4: Kindly provide complete page range for reference 6.

AQ5: Kindly provide location for references 7, 9, and 15-20.

AQ6: Kindly confirm whether the corresponding author information is OK as typeset. 